\title{
A Comprehensive Review of Methods to Measure Oral Oncolytic Dose Intensity Using Retrospective Data
}

\author{
Julia F. Slejko, PhD; Juan-David Rueda, MD, MS, PhD; James A. Trovato, PharmD, MBA, BCOP; \\ Emily F. Gorman, MLIS; Gail Betz, MLIS; Stephen Arcona, PhD; Christopher Zacker, PhD; \\ and Bruce Stuart, PhD
}

\begin{abstract}
BACKGROUND: Understanding the real-world use of oral oncolytics is essential to assess drug effectiveness. Retrospective analyses using medical and pharmacy claims data allow observation of drug use patterns and health outcomes. However, studies of medication adherence to oral oncolytics may not be sufficient in characterizing exposure because they typically measure refill frequency, not the administered dose or dose changes. Patients who appear fully adherent by traditional measures may be receiving different doses and experiencing differing effectiveness. Relative dose intensity (RDI) is a measure that has been used for intravenous drugs to capture the amount of a particular chemotherapeutic agent administered per unit of time (dose intensity), expressed as the fraction of the amount recommended in evidence-based guidelines. Such a measure would be useful for real-world studies of comparative effectiveness to characterize patient exposure to oral oncolytics.
\end{abstract}

OBJECTIVE: To identify studies that used administrative claims data to measure real-world oral oncolytic dose intensity, RDI, or similar constructs.

METHODS: Two health sciences librarians conducted a literature search (PubMed, January 1, 1809-February 6, 2018) including terms in each of the following concept areas: oncology drugs, dosage, and retrospective data sources. At least 2 reviewers scanned each title and abstract of publications retrieved from PubMed. Abstracts that indicated the study reported dose or related concepts and oral oncolytics using retrospective data sources were marked for full-text review. During full-text review, papers were excluded if they did not study oral oncolytics (i.e., only described intravenous chemotherapy); if they did not report drug dosage; or if the study was not retrospective. Resulting studies were included for full-text data extraction.

RESULTS: Of the 1,640 publications returned from the search, 41 were marked for full-text review. Full-text review established that 17 studies addressed a concept related to dose of oral oncolytics using retrospective data. Twenty-four studies were excluded: 11 did not measure dose; 9 did not study oral oncolytics; and 4 were not retrospective studies. Among the 17 articles marked for extraction, 5 articles reported dose intensity or RDI using medical records or electronic health record (EHR) data.

CONCLUSIONS: This study reveals not only the need for a claims-based measure of dose intensity for oral oncolytics, but also provides a basis for the development of such a measure based on previous EHR-based studies. While several claims data studies have characterized oral oncolytic dosing and duration, we found that no studies combined these dimensions into a single measure such as dose intensity. Methods using EHR data may be translatable to a claims data study. Future research is needed to develop and validate such measures.

J Manag Care Spec Pharm. 2019;25(10):1125-32

Copyright $\odot 2019$, Academy of Managed Care Pharmacy. All rights reserved.

\section{What is already known about this subject}

Characterizing real-world use of oral oncolytics is essential to assess drug effectiveness.

Many oral oncolytics are distributed through pharmacies, which results in administrative claims data for reimbursement and allows for utilization studies of retrospective medical and pharmacy claims data.

\section{What this study adds}

While many retrospective studies characterize treatments patterns or adherence (using refill data), few address medication dosage. This study illustrates a need for measures and methods that use retrospective claims data to capture dose intensity of oral oncolytics. Studies identifying dose intensity using medical records may serve as a basis for future methods development.

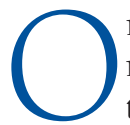
ral medications are increasingly used for cancer treatment. Because these drugs are often dispensed in the pharmacy, prescription refill data can be used to understand their real-world use, which is essential to assess drug effectiveness. Retrospective analyses using administrative medical and pharmacy claims data from public and private payers allow observation of drug use patterns and health outcomes and are commonly used for outcomes research. Because oral oncolytics are used for some long-term treatments, studies of medication adherence have appeared in the literature to characterize this use. The term "adherence" refers to the agreement between patients and providers about what medication is chosen, as well as the dosage and frequency. ${ }^{1,2}$

Real-world studies of medication adherence that use prescription refill data from administrative pharmacy claims typically report measures such as medication possession ratio (MPR), which measures the number of doses dispensed over the entire refill period. ${ }^{1-3}$ This measure has been used extensively to characterize whether patients are adherent to their chronic conditions medications. While understanding patient adherence (i.e., whether patients took their medications as prescribed) is an important concept ${ }^{4}$ typically used adherence measures do not consider administered dose of medications or titrations that may occur. Persistence, or the duration of therapy, is also important in assessing oral oncolytic therapy, 


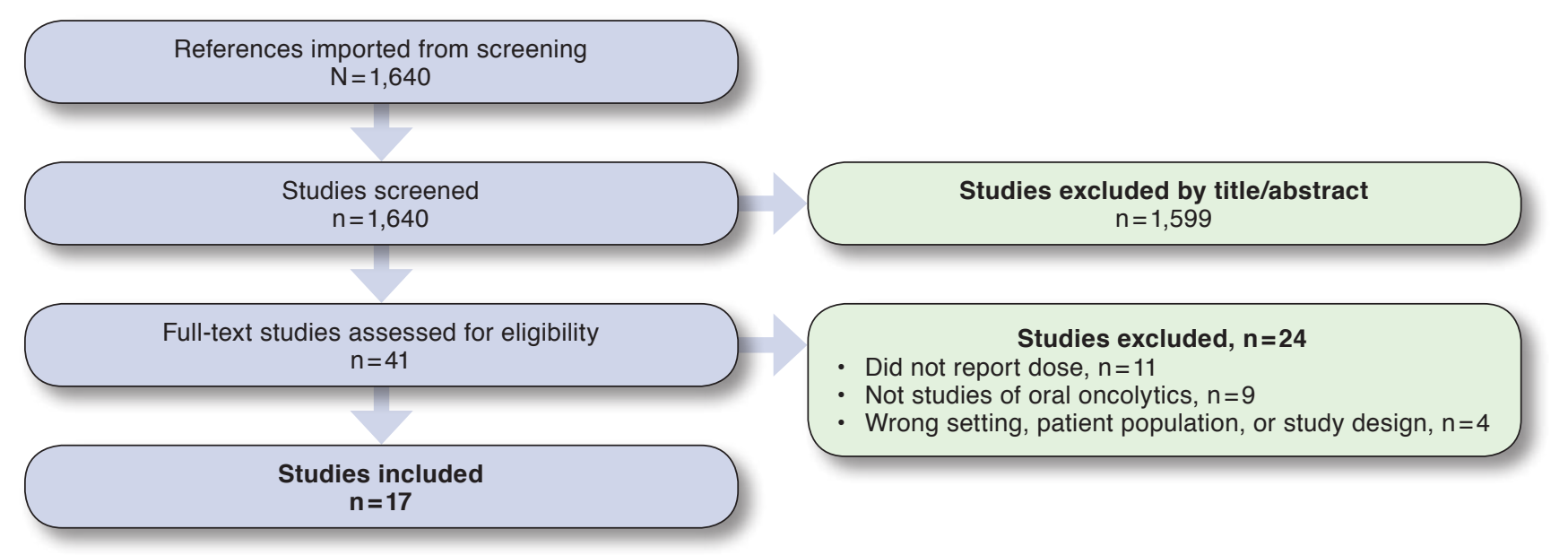

PRISMA = Preferred Reporting Items for Systematic Reviews and Meta-Analyses.

since it allows examination of overall time on treatment as opposed to a proportion of prescriptions filled over time. Dosing may be more individualized in the oncology setting, and traditional measures of adherence are not sufficient to assess exposure because they do not capture dose or dose adjustments that are commonly employed.

Dose intensity is a measure that has been used to capture the amount of a particular chemotherapeutic agent administered per unit of time and is associated with patient outcomes, including survival., ${ }^{5,6}$ Relative dose intensity (RDI) expresses dose intensity as the fraction of the amount recommended, that is, the dose administered relative to the standard dose indicated in a protocol or in evidence-based guidelines. ${ }^{7}$ This measure is used commonly in the literature assessing intravenous chemotherapy safety and efficacy. ${ }^{8}$ Measures such as dose intensity or RDI would be useful to measure the dimensions of medication frequency, dose, and duration using claims data, but it is unclear whether claims-based dose intensity or RDI measures have been used to analyze oral oncolytic use.

The primary objective of our review was to identify studies that used pharmacy claims data to measure real-world oral oncolytic dose intensity, RDI, or similar constructs. Our secondary objective was to describe studies whose methods could be modified to assess dose intensity, RDI, or similar constructs.

\section{Methods}

\section{Literature Search Strategy}

Two health sciences librarians (EFG and GB) conducted literature searches using the PubMed database (January 1, 1809-February 6, 2018). The search strategies included terms in each of the following concept areas: oncolytics, dosage, and claims data (including other retrospective data such as medical records and registries). In a pilot search to test the scope of available literature, the claims category was narrowed to include just 1 subject heading and 1 keyword related to administrative claims. Three reviewers (JDR, JFS, and JAT) independently scanned the resulting publications returned from the PubMed pilot search $(n=165)$ and assessed each title for its relevance to the study question. Then, 1 team member (JDR) reviewed the 165 abstracts to assess agreement. The full text of several abstracts that appeared likely to address the study question was used to adjust the methods and keywords for the full search. See the Appendix (available in online article) for the full PubMed search strategy. Study selection, analysis, and reporting were conducted in accordance with PRISMA guidelines. ${ }^{9}$

\section{Eligibility}

We included retrospective studies that reported dosing patterns, dose changes, starting dose, RDI, or dose intensity of oral oncolytic drug therapy. Eligible studies needed to report drug dose as one of their measures. Publications were excluded if they (a) were not studies of human subjects; (b) were clinical studies of safety or efficacy; (c) did not use a retrospective data source (e.g., administrative claims, electronic health record (EHR) data, or medical records); (d) did not address medication dose in study measures; or (e) did not reference oral oncolytics.

\section{Search Strategy and Extraction}

The study team used a multistep process to select papers for full-text review. At least 2 reviewers (JDR, JFS, or JAT) independently scanned the resulting publication title and abstracts returned from the PubMed full search using Covidence systematic review software (Veritas Health Innovation, Melbourne, Australia) to determine eligibility using the criteria previously 


\section{TABLE 1 Characteristics of Retrospective Studies Examining Dose, Dose Intensity,} or RDI of Oral Oncolytics

\begin{tabular}{|c|c|c|c|c|c|c|}
\hline Author & Country & Data Source & Cancer Type & Drugs Studied & Dose Characterization & Study Outcomes \\
\hline $\begin{array}{l}\text { Bendaly et al., } \\
20177^{19}\end{array}$ & United States & $\begin{array}{l}\text { Medical records obtained from } \\
\text { oncologists associated with Cardinal } \\
\text { Health Specialty Solutions }\end{array}$ & $\begin{array}{l}\text { Small cell } \\
\text { lung cancer }\end{array}$ & Ceritinib & Dose reductions & $\begin{array}{l}\text { Treatments, dosing } \\
\text { patterns, and early } \\
\text { outcomes }\end{array}$ \\
\hline $\begin{array}{l}\text { Castellano et al., } \\
2013^{24}\end{array}$ & Spain & $\begin{array}{l}\text { Medical records at Hospital del } \\
\text { Mar in Barcelona and Hospital } \\
\text { Universitario } 12 \text { de Octubre in } \\
\text { Madrid, Spain }\end{array}$ & $\begin{array}{l}\text { Renal cell } \\
\text { carcinoma }\end{array}$ & $\begin{array}{l}\text { Sunitinib, } \\
\text { sorafenib }\end{array}$ & $\begin{array}{l}\text { RDI, discontinuation, } \\
\text { interruption, or dose } \\
\text { change }\end{array}$ & Treatment patterns \\
\hline $\begin{array}{l}\text { Choueiri et al., } \\
2010^{12}\end{array}$ & United States & $\begin{array}{l}\text { Renal Clinical Research Information } \\
\text { System at Beth Israel Deaconess } \\
\text { Medical Center and Dana-Farber } \\
\text { Cancer Institute, Boston, MA }\end{array}$ & $\begin{array}{l}\text { Renal cell } \\
\text { carcinoma }\end{array}$ & $\begin{array}{l}\text { Sunitinib, } \\
\text { sorafenib, } \\
\text { bevacizumab }\end{array}$ & $\begin{array}{l}\text { Dose interruption, } \\
\text { reduction, or increase }\end{array}$ & $\begin{array}{l}\text { Safety and treatment } \\
\text { patterns }\end{array}$ \\
\hline $\begin{array}{l}\text { Darkow et al., } \\
200720\end{array}$ & United States & $\begin{array}{l}\text { Electronic pharmacy, enrollment } \\
\text { data, and medical claims from a U.S. } \\
\text { managed care provider }\end{array}$ & $\begin{array}{l}\text { Chronic } \\
\text { myeloid } \\
\text { leukemia }\end{array}$ & Imatinib & $\begin{array}{l}\text { Treatment } \\
\text { interruption } \\
\text { and medication } \\
\text { nonadherence (MPR) } \\
\end{array}$ & Health care costs \\
\hline $\begin{array}{l}\text { Gelderblom } \\
\text { et al., } 201725\end{array}$ & $\begin{array}{l}\text { Australia, } \\
\text { Greece, Israel, } \\
\text { Italy, the } \\
\text { Netherlands } \\
\text { and the United } \\
\text { Kingdom }\end{array}$ & $\begin{array}{l}\text { Multicountry, multicenter, } \\
\text { retrospective chart review }\end{array}$ & $\begin{array}{l}\text { Soft tissue } \\
\text { sarcomas }\end{array}$ & Pazopanib & $\begin{array}{l}\text { RDI, mean starting } \\
\text { dose, percentage of } \\
\text { patients with dose } \\
\text { reductions, treatment } \\
\text { duration }\end{array}$ & $\begin{array}{l}\text { Treatment patterns, } \\
\text { effectiveness, and } \\
\text { adverse events }\end{array}$ \\
\hline $\begin{array}{l}\text { Hess et al., } \\
2013^{10}\end{array}$ & United States & $\begin{array}{l}\text { SDI Health, now part of IMS Health, } \\
\text { Plymouth Meeting, PA }\end{array}$ & $\begin{array}{l}\text { Renal cell } \\
\text { carcinoma }\end{array}$ & $\begin{array}{l}\text { Sunitinib, } \\
\text { sorafenib, } \\
\text { temsirolimus }\end{array}$ & $\begin{array}{l}\text { Treatment patterns, } \\
\text { duration of therapy, } \\
\text { dosing patterns, and } \\
\text { treatment changes; } \\
\text { percentage of } \\
\text { prescriptions unfilled, } \\
\text { escalated, maintained, } \\
\text { and reduced } \\
\end{array}$ & $\begin{array}{l}\text { Treatment patterns } \\
\text { and dosing }\end{array}$ \\
\hline $\begin{array}{l}\text { Lafeuille et al., } \\
201421\end{array}$ & United States & $\begin{array}{l}\text { Truven Health Analytics MarketScan } \\
\text { Commercial Claims and Encounters } \\
\text { and Medicare Supplemental Dataset } \\
\text { (December 2010-August 2012) and } \\
\text { Symphony Health Solutions ProMetis } \\
\text { Lx (June 2009-March 2013). }\end{array}$ & $\begin{array}{c}\text { Prostate } \\
\text { cancer }\end{array}$ & Abiraterone & $\begin{array}{l}\text { Adherence patterns } \\
\text { (MPR), daily dose }\end{array}$ & $\begin{array}{l}\text { Utilization and } \\
\text { adherence }\end{array}$ \\
\hline $\begin{array}{l}\text { Latremouille- } \\
\text { Viau et al., } \\
2017^{22}\end{array}$ & United States & $\begin{array}{l}\text { Two large U.S. administrative claims } \\
\text { databases }\end{array}$ & $\begin{array}{l}\text { Chronic } \\
\text { myeloid } \\
\text { leukemia }\end{array}$ & $\begin{array}{l}\text { Dasatinib, } \\
\text { nilotinib }\end{array}$ & $\begin{array}{l}\text { Dose decrease or } \\
\text { increase, treatment } \\
\text { discontinuation, } \\
\text { treatment switch, } \\
\text { adherence } \\
\end{array}$ & $\begin{array}{l}\text { Treatment patterns, } \\
\text { adherence to TKI } \\
\text { therapy, HRU, and } \\
\text { health care cost }\end{array}$ \\
\hline Lu et al., 201715 & Taiwan & $\begin{array}{l}\text { NHI research database (NHIRD) and } \\
\text { diagnosis of HCC from the Taiwan } \\
\text { Cancer Registry }\end{array}$ & $\begin{array}{c}\text { Hepatocellular } \\
\text { carcinoma }\end{array}$ & Sorafenib & \begin{tabular}{|l} 
Treatment \\
discontinuation, \\
initial dose, time to \\
discontinuation \\
\end{tabular} & $\begin{array}{l}\text { Prescription patterns } \\
\text { and treatment } \\
\text { outcomes }\end{array}$ \\
\hline $\begin{array}{l}\text { MacLean et al., } \\
2016^{11}\end{array}$ & United States & $\begin{array}{l}\text { Specialty Pharmacy Data Mart, and } \\
\text { IMS-managed database }\end{array}$ & $\begin{array}{l}\text { Renal cell } \\
\text { carcinoma }\end{array}$ & $\begin{array}{l}\text { Axitinib, } \\
\text { pazopanib }\end{array}$ & $\begin{array}{l}\text { Discontinuation, } \\
\text { dose increase, dose } \\
\text { decrease, and/or both }\end{array}$ & $\begin{array}{l}\text { Patient } \\
\text { characteristics, } \\
\text { treatment patterns, } \\
\text { dosing, treatment } \\
\text { line, duration of } \\
\text { therapy } \\
\end{array}$ \\
\hline $\begin{array}{l}\text { Mitra et al., } \\
2012^{16}\end{array}$ & $\begin{array}{l}\text { United States, } \\
\text { Japan, United } \\
\text { Kingdom, } \\
\text { Germany }\end{array}$ & Medical records & $\begin{array}{l}\text { Chronic } \\
\text { myeloid } \\
\text { leukemia }\end{array}$ & $\begin{array}{l}\text { Imatinib, } \\
\text { dasatanib, } \\
\text { nilotinib, }\end{array}$ & $\begin{array}{l}\text { Dose escalation, } \\
\text { highest daily } \\
\text { dose, reason for } \\
\text { discontinuation } \\
\end{array}$ & $\begin{array}{l}\text { Treatment patterns, } \\
\text { choice of drugs, } \\
\text { clinical outcomes, } \\
\text { adverse events }\end{array}$ \\
\hline Pal et al., $2016^{17}$ & United States & Medical records & $\begin{array}{l}\text { Renal cell } \\
\text { carcinoma }\end{array}$ & $\begin{array}{l}\text { Everolimus, } \\
\text { axitinib }\end{array}$ & $\begin{array}{l}\text { Dose escalation, dose } \\
\text { de-escalation }\end{array}$ & $\begin{array}{l}\text { Dosing patterns and } \\
\text { drug costs }\end{array}$ \\
\hline $\begin{array}{l}\text { Porta et al., } \\
201426\end{array}$ & \begin{tabular}{|c|} 
France, Ireland, \\
Italy, Spain, \\
United \\
Kingdom
\end{tabular} & $\begin{array}{l}\text { Medical records from multiple } \\
\text { European countries }\end{array}$ & $\begin{array}{l}\text { Renal cell } \\
\text { carcinoma }\end{array}$ & Sunitinib & $\begin{array}{l}\text { Dose reductions, } \\
\text { interruptions, } \\
\text { discontinuation, dose } \\
\text { intensity, RDI }\end{array}$ & $\begin{array}{l}\text { Adverse events, } \\
\text { treatment } \\
\text { modifications, dose } \\
\text { intensity, overall } \\
\text { survival } \\
\end{array}$ \\
\hline
\end{tabular}




\begin{tabular}{|c|c|c|c|c|c|c|}
\hline Author & Country & Data Source & Cancer Type & Drugs Studied & Dose Characterization & Study Outcomes \\
\hline $\begin{array}{l}\text { Saleh et al., } \\
201413\end{array}$ & United States & $\begin{array}{l}\text { EMR and patient management system } \\
\text { (OASIS) integrated with the billing } \\
\text { system of Georgia Cancer Specialists }\end{array}$ & $\begin{array}{l}\text { Chronic } \\
\text { myeloid } \\
\text { leukemia }\end{array}$ & Imatinib & $\begin{array}{l}\text { Treatment } \\
\text { patterns, dose } \\
\text { increase, decrease, } \\
\text { discontinuation, and } \\
\text { switch rates }\end{array}$ & $\begin{array}{l}\text { Treatment } \\
\text { patterns, including } \\
\text { dose increase, } \\
\text { dose decrease, } \\
\text { discontinuation, } \\
\text { and switch, the } \\
\text { monitoring rate, and } \\
\text { treatment response }\end{array}$ \\
\hline $\begin{array}{l}\text { Schnadig et al., } \\
201423\end{array}$ & United States & $\begin{array}{l}\text { EMR of } 17 \text { McKesson Specialty } \\
\text { Health/U.S. Oncology Network } \\
\text { practices }\end{array}$ & $\begin{array}{l}\text { Renal cell } \\
\text { carcinoma }\end{array}$ & Sunitinib & $\begin{array}{l}\text { Dose intensity, } \\
\text { frequency of } \\
\text { dose reductions, } \\
\text { dose delays, } \\
\text { schedule changes, } \\
\text { discontinuations }\end{array}$ & $\begin{array}{l}\text { Frequency of } \\
\text { dose reductions, } \\
\text { dose delays, } \\
\text { schedule changes, } \\
\text { discontinuations, } \\
\text { toxicities, and } \\
\text { outcomes }\end{array}$ \\
\hline $\begin{array}{l}\text { Shingina et al., } \\
2013^{18}\end{array}$ & Canada & $\begin{array}{l}\text { A retrospective chart review of } 99 \\
\text { patients referred to the clinic at } \mathrm{BC} \\
\text { Cancer Agency }\end{array}$ & $\begin{array}{c}\text { Hepatocellular } \\
\text { carcinoma }\end{array}$ & Sorafenib & $\begin{array}{l}\text { Dose reductions, time } \\
\text { to dose reduction, } \\
\text { duration of treatment, } \\
\text { discontinuation }\end{array}$ & $\begin{array}{l}\text { Effectiveness and } \\
\text { tolerance }\end{array}$ \\
\hline $\begin{array}{l}\text { Stenehjem et al., } \\
201414\end{array}$ & United States & $\begin{array}{l}\text { Electronic data warehouse for the } \\
\text { University of Utah Health Care, } \\
\text { which includes Huntsman Cancer } \\
\text { Institute }\end{array}$ & $\begin{array}{l}\text { Chronic } \\
\text { myeloid } \\
\text { leukemia }\end{array}$ & Imatinib & $\begin{array}{l}\text { Dose escalation, } \\
\text { reductions, } \\
\text { discontinuation }\end{array}$ & $\begin{array}{l}\text { Treatment patterns } \\
\text { and monitoring } \\
\text { adverse events }\end{array}$ \\
\hline
\end{tabular}

EMR=electronic medical record; HCC=hepatocellular carcinoma; HRU = health care resource utilization; $M P R=$ medication possession ratio; NHIRD =National Health Insurance Research Database; RDI = relative dose intensity; TKI = tyrosine kinase inhibitor.

described. Tags were added to papers that contained 1 or more of the following concepts: dose change, starting dose, adherence, persistence, duration, discontinuation, treatment pattern, RDI, and dose intensity. Conflicts arising during title and abstract review were resolved by 2 reviewers (JDR and JFS). Papers that appeared to include the concepts of dose intensity, RDI, dose, and/or duration were retained for full-text review.

During full-text review (JFS and JDR), additional papers were excluded that did not meet the previously described inclusion criteria. Figure 1 displays the PRISMA diagram for identification of eligible studies included in our review. ${ }^{9}$ After identifying eligible studies, the following data elements were extracted from each full-text publication: author, year, country, data source, cancer type, drugs studied, dose characterization (e.g., dose intensity and RDI) and primary study outcomes.

\section{Results}

\section{Description of Literature}

A total of 1,640 abstracts were screened, of which 41 were selected for full-text review. Full-text review established that 17 studies were eligible for extraction (Table 1). Twenty-four studies were excluded during full-text review because they did not measure dose $(n=11)$, did not study oral oncolytics $(n=9)$, or were not retrospective studies $(n=4)$. Among the 17 articles included in our review, 11 were conducted in the United States, 5 were conducted outside the United States, and 1 was conducted across multiple countries including the United States. The most common cancers studied were renal cell carcinoma (RCC; $\mathrm{n}=7$ ) and chronic myeloid leukemia (CML; $\mathrm{n}=4$; Table 1).

\section{Summary of Literature}

Studies Reporting Dose Using Administrative Claims Data Sources. Of 5 studies that used administrative claims, 2 focused specifically on drug dose and concepts related to dose. Hess et al. (2013) studied real-world use of targeted therapies for RCC in U.S. claims data and reported starting dose, duration of therapy, and whether patients continued, switched, or added therapies over time..$^{10}$ MacLean et al. (2016) also published a study of real-world treatment of RCC and reported duration of therapy, daily dose, and whether the dose was modified after therapy initiation as separate measures. ${ }^{11}$

Studies Reporting Dose Using EHR and Other Medical Record Data Sources. Eight EHR or medical record studies reported dose and related concepts but did not specifically report dose intensity or RDI. Choueiri et al. (2010) performed a medical record review from 2 oncology centers in the United States and described initial doses of sunitinib and sorafenib for RCC, as well as subsequent dose changes but not dose intensity.12 Saleh et al. (2014) used electronic medical record (EMR) data to study treatment patterns and outcomes for CML patients using imatinib and reported starting dose. ${ }^{13}$ Stenehjem et al. (2014) used retrospective EHR review methods 
to study first-line imatinib for CML treatment, reporting dose modifications in relation to the initial dose. ${ }^{14}$ Lu et al. (2017) used the National Health Insurance Research Database of Taiwan to analyze prescription patterns of sorafenib in patients with advanced hepatocellular carcinoma. ${ }^{15}$ They described variation in initial starting dose and subsequent modifications. Their related analyses looked at predictors of standard initial dose and whether standard initial dose was an independent predictor of overall survival, adjusting for covariates. Mitra et al. (2012) performed medical record abstraction and reported characteristics and treatment patterns of patients with CML using imatinib and either dasatinib or nilotinib, as well as the characteristics of their physicians. ${ }^{16}$ Starting daily dose of each drug, dose escalation, highest daily dose, and treatment duration were reported. Pal et al. (2016) also conducted a medical record review of patients with RCC using axitinib or everolimus after discontinuation of a tyrosine kinase inhibitor. ${ }^{17}$ Their study mainly focused on costs but also reported whether patients' initiation dose was with the recommended dose and whether dose adjustments were made. Shingina et al. (2013) used a chart review to assess sorafenib use in RCC patients, reporting initial dose, treatment duration, and outcomes. ${ }^{18}$ Bendaly et al. (2017) used a chart review process to characterize treatments and dosing patterns of ceritinib for small-cell lung cancer, reporting starting dose and subsequent dose reductions along with reports of adverse events, progressionfree survival, and clinical response. ${ }^{19}$

Studies of Adherence and/or Persistence and Dose. Our search returned 3 adherence studies that also mentioned dose (and were therefore eligible for inclusion in our study). Darkow et al. (2007) studied nonadherence to imatinib and treatment interruptions and associated health care costs using health care claims data. ${ }^{20}$ This study assessed MPR as the measure of adherence using medication refills and addressed imatinib starting dose as a potential characteristic associated with adherence. Lafeuille et al. (2014) studied adherence patterns of patients using abiraterone acetate and concomitant prednisone using claims data, reporting MPR and mean daily dose per patient. ${ }^{21}$ Latremouille-Viau et al. (2017) used claims data to describe treatment patterns and adherence for CML patients using dasatinib or nilotinib. ${ }^{22}$ Dose increases or decreases, as compared with the initial dose, were identified. Average daily dose was reported, as well as whether doses were lower or higher than recommended.

Studies Specifically Reporting Dose Intensity and/or RDI. Schnadig et al. (2014) used EMR data from U.S. oncology practices in their study of first-line sunitinib treatment for RCC. ${ }^{23}$ Dose intensity was one of their main study outcomes, in addition to dose reductions, delays, discontinuation, and other treatment patterns. The authors did not provide a formula to calculate dose intensity. It was likely a variable available in their data source. Three chart review studies reported dose intensity or RDI. Castellano et al. (2013) performed a medical record review for patients treated with sunitinib and sorafenib for RCC at Spanish hospitals. ${ }^{24}$ They calculated RDI as the actual average daily dose of drug divided by the optimal or recommended dose found in the prescribing information. Gelderblom et al. (2017) used a multicountry, multicenter chart review approach to study the use of pazopanib for treatment of advanced soft tissue sarcoma. ${ }^{25}$ This study did report RDI as a ratio of the mean daily dose as compared with the recommended starting dose, with the purpose of assessing treatment patterns, effectiveness, and adverse events. Porta et al. (2014) conducted a cohort study among several European countries and used medical records to assess dose intensity of sunitinib for treatment of RCC. ${ }^{26}$ They calculated dose intensity as the actual daily dose divided by the optimal or recommended daily dose.

During full-text review, we identified a number of studies that, while not meeting the criteria for full-text review, did provide a basis for future methods work in this area. Three studies used retrospective data sources such as EHR data to calculate RDI, although they did not study oral drugs. ${ }^{27-29}$ Jonasch et al (2016) used medical records to characterize RCC treatment patterns and reported whether patients had dose adjustments but did not report the dose itself. ${ }^{30}$ Tan et al. (2015) reported efficacy and safety of sunitinib in a single-center study and was specifically focused on dosing strategies. ${ }^{31}$ These 2 studies would contribute to understanding individualized dosing of these treatments.

\section{Discussion}

We aimed to identify methods using pharmacy claims data to measure dose intensity, RDI, or similar constructs for studies of oral oncolytics in real-world practice. While there were a number of claims-based studies that reported dose, none characterized dose with a measure such as dose intensity or RDI. We found 17 studies that assessed dose, dose intensity, or RDI of oral oncolytics using any retrospective data source (administrative claims, EHR, or other medical record review). One study specifically mentioned that there are limited data on RDI from observational studies for RCC. ${ }^{24}$ One study using EHR data specifically reported dose intensity and several chart review studies described RDI. ${ }^{23-26}$ While we aimed to specifically identify claims-based methods, these EHR and chart reviews are useful for future methods development and may be applicable to future methods studies using claims data.

While some of the studies we found characterized treatment patterns, many aimed to associate treatment patterns with tolerability, safety, and survival outcomes. ${ }^{32}$ When comparing oral oncolytic treatment outcomes using administrative claims data, it is critical to understand whether patients were adherent to their therapy, as well as initial dose and dose changes resulting from tolerability, adverse events, or progression. A 
measure of dose intensity or RDI would capture individualized dose changes that would enhance characterization of exposure and its association with outcomes. Engle et al. (2018) discussed the issue of reduced RDI as a potential source of bias in clinical trials because patients enrolled in cancer clinical trials may not achieve dose intensity specified in the trial, and efficacy and/or adverse effects associated with a particular dose may be underestimated. ${ }^{8}$ Claims-based studies may be subject to similar bias that could be reduced with better measures of dose and dose changes.

Pharmacy claims data are often used for understanding factors associated with adherence to oral oncolytics for longterm treatment and subsequent outcomes; however, traditional adherence studies commonly focus on refill frequency and not the dose of the medication. Including dose intensity measures to adherence studies that focus on refills, especially those that consider factors related to adherence or adherence improvement, ${ }^{33,34}$ could potentially reveal whether dose changes also occurred when adherence increased or decreased. In studies that link adherence to outcomes, measures that include dose or duration at a particular dose may lead to better estimates of drug effectiveness. Several studies did not calculate dose intensity but reported data about dose that appeared to allow for such a calculation, relative to the recommended or starting dose. For example, Lafeuille et al. reported MPR and mean daily dose per patient but not relative to guidelines or recommended dosing in a single metric such as RDI. ${ }^{21}$ LatremouilleViau et al. reported average daily dose, as well as whether it was lower or higher than recommended. ${ }^{22}$ Darkow et al. examined whether the imatinib starting dose was a potential characteristic associated with adherence. This association was significant in their base analysis, which suggests that a measure of dose intensity would be warranted in this setting. ${ }^{20}$

A measure of RDI necessitates the comparison with a planned dose, which is unobservable in claims data, but as suggested by several of the papers found in our search, treatment guidelines may be used. Alternatively, assuming the prescriber calculated the optimal and appropriate dose for a given patient, the initial starting dose could also be considered as a denominator value. Three chart review studies reported RDI and used the following 2 approaches: (1) divide the actual average daily dose of drug by the optimal or recommended dose found in the prescribing information ${ }^{24,26}$ or (2) report RDI as a ratio of the mean daily dose as compared with the recommended starting dose. ${ }^{25}$ It appears that the elements needed to perform the calculation of dose intensity and RDI are available in claims data (i.e., dose and duration), in addition to the recommended dose found in guidelines or labeling. A methods study using claims data could confirm this as a possible approach. Validation using EHR data would further strengthen such a measure.

Two studies are particularly helpful for future methods development. ${ }^{8,35}$ Amlani et al. (2016) compared adherence measures using administrative data versus medical record data and found a number of differences. ${ }^{35}$ The authors enriched the claims data with EMRs to identify patients with intentional treatment delays or inappropriate treatment delays. The results from this study show that $84 \%$ of the treatment delays were intentional, and if only administrative data would have been used, these patients would have been incorrectly assessed. This highlights the importance of considering individualized dosing and using methods that can detect dose changes. It will be important to discern the differences between a claims-based or EHR-based measure of RDI and what limitations may exist for claims-based studies.

Engle et al. described 4 related measures of dose intensity for clinical trial analysis that could be tested in claims data or EHRlinked claims data. ${ }^{8}$ Adjusted dose intensity captured provider- or protocol-specified dose reductions as total milligrams per cycle Planned dose intensity was calculated using the trial protocol dose per day and cycle duration. Patient-specific dose intensity was the actual amount of medication taken by the patient as measured by pill counts or patient diaries. The RDI was then calculated by dividing the patient-specific dose intensity by the planned dose intensity and multiplying by 100 . This incorporates the concept of patient medication adherence as well because it measures not only the planned dose, but the actual dose that was reported as consumed by the patient. ${ }^{8}$ Engle's method could be translated to a retrospective claims analysis with several considerations: The planned DI and provider-specified dose reductions are unknown unless observed in EHR-linked data, but as previously mentioned, guidelines or labeling could serve as a reference for comparison (e.g., National Comprehensive Cancer Network, American Society of Clinical Oncology, or European Society for Medical Oncology). The patient-specific dose intensity could easily be captured using pharmacy claims with several potential limitations. As is the case with all retrospective studies using claims data, one can only observe prescriptions that are actually filled. Primary nonadherence, prescriptions that are never filled by patients, is not observable and would potentially bias measures of dose intensity.

\section{Implications}

Understanding the real-world use of oral oncolytics, used increasingly for cancer treatment, is essential to assess real-world drug effectiveness and comparative effectiveness. Retrospective analyses using medical and pharmacy claims data allow observation of dose, drug utilization patterns, and health outcomes over time frames longer than most clinical trials in larger and broader real-world populations. It appears that enhanced measures of oral oncolytic use may helpful. Patients may receive individualized dose changes, and these changes in drug exposure could lead to changes in observed effectiveness. Patients who exhibit similar "adherence" by traditional measures of refill frequency may be using different doses of drugs; therefore, they may experience different therapeutic benefits. Measures of refill 
frequency, so commonly used for measuring adherence, are not sufficient to capture exposure because they do not consider continuous time on therapy or dose changes. Future methods research should work toward creating measures that capture medication starting dose, changes in dose over time, and daily exposure and discontinuation (already reflected in traditional adherence measures). These measures would not only enhance characterization of adherence or treatment patterns, but would be valuable for comparative effectiveness studies. Enriched data sources such as administrative claims linked to EHR data would allow better characterization of observed dose changes because it would allow assessment of individualized dosing, disease progression, and other clinical factors. These data would provide an ideal setting for methods validation.

\section{Limitations}

We did not include references from other sources, such as Embase, which could be viewed as a limitation. We decided to exclude these references because of the resources available to review the references and the sheer volume of references retrieved in Embase. The full search (as described in the Methods section) performed in Embase retrieved 5,958 citations, after removing duplicates that already appeared in the PubMed search. We felt that the PubMed search, returning over 1,600 citations, while perhaps not including every retrospective study of oral oncolytics, would likely provide a good representation of the methods currently in use by researchers.

\section{Conclusions}

Our literature review revealed that there is a need for enhanced measures of oral oncolytic use that include adherence and dose for use in retrospective studies. EHR-linked claims data would allow development and validation of more comprehensive measures. A measure of dose intensity or RDI for oral oncolytics would provide a valuable measure for future oncology outcomes research studies.

\section{Authors}

JULIA F. SLEJKO, PhD; JUAN-DAVID RUEDA, MD, MS, PhD; JAMES A. TROVATO, PharmD, MBA, BCOP; and BRUCE STUART, PhD, Department of Pharmaceutical Health Services, University of Maryland School of Pharmacy, Baltimore. EMILY F. GORMAN, MLIS, and GAIL BETZ, MLIS, Health Sciences and Human Services Library, University of Maryland, Baltimore. STEPHEN ARCONA, PhD, and CHRISTOPHER ZACKER, PhD, Novartis Pharmaceuticals, East Hanover, New Jersey.

AUTHOR CORRESPONDENCE: Julia F. Slejko, PhD, Department of Pharmaceutical Health Services Research, University of Maryland School of Pharmacy, 220 Arch St., 12th Fl., Baltimore, MD 21201. Tel.: 410.706.5397; E-mail: jslejko@rx.umaryland.edu.

\section{DISCLOSURES}

Novartis Pharmaceuticals provided funding for this study and is a manufacturer of oral onalytics, which is under study in this article. Arcona and Zacker are employees of Novartis. Slejko reports grants from PhRMA, PhRMA Foundation, and Takeda Pharmaceuticals and consulting fees from Pfizer, outside the submitted work. Stuart reports consulting fees from the University of Maryland during the study. The other authors have nothing to disclose.

The preliminary findings of this study were presented in a poster at AMCP Nexus 2018, October 22-25, 2018, in Orlando, FL.

\section{REFERENCES}

1. Greer JA, Amoyal N, Nisotel L, et al. A systematic review of adherence to oral antineoplastic therapies. Oncologist. 2016;21(3):354-76. Available at: http://theoncologist.alphamedpress.org/content/21/3/354.long. Accessed August 15, 2019.

2. Cramer JA, Roy A, Burrell A, et al. Medication compliance and persistence: terminology and definitions. Value Health. 2008;11(1):44-47. Available at: https://www.valueinhealthjournal.com/article/S1098-3015(10)60495-0/pdf? returnURL=https $\% 3 \mathrm{~A} \% 2 \mathrm{~F} \% 2 \mathrm{Flinkinghub}$.elsevier.com $\% 2$ Fretrieve $\% 2 \mathrm{Fpii} \% 2 \mathrm{~F}$ S1098301510604950\%3Fshowall\%3Dtrue. Accessed August 15, 2019.

3. Andrade SE, Kahler KH, Frech F, Chan KA. Methods for evaluation of medication adherence and persistence using automated databases. Pharmacoepidemiol Drug Saf. 2006;15(8):565-74. Available at: https://onlinelibrary.wiley.com/doi/abs/10.1002/pds.1230. Accessed August 15, 2019.

4. Yeaw J, Benner JS, Walt JG, Sian S, Smith DB. Comparing adherence and persistence across 6 chronic medication classes. J Manag Care Pharm. 2009;15(9):728-40. Available at: https://www.jmcp.org/doi/10.18553/ jmcp.2009.15.9.728.

5. Bosly A, Bron D, Van Hoof A, et al. Achievement of optimal average relative dose intensity and correlation with survival in diffuse large B-cell lymphoma patients treated with CHOP. Ann Hematol. 2008;87(4):277-83.

6. Brunetto AT, Carden CP, Myerson J, et al. Modest reductions in dose intensity and drug-induced neutropenia have no major impact on survival of patients with non-small cell lung cancer treated with platinum-doublet chemotherapy. J Thorac Oncol. 2010;5(9):1397-403.

7. Hryniuk W. The importance of dose intensity in the outcome of chemotherapy. Important Adv Oncol. 1988:121-41.

8. Engle JA, Traynor AM, Campbell TC, et al. Assessment of adherence and relative dose intensity with oral chemotherapy in oncology clinical trials at an academic medical center. J Oncol Pharm Pract. 2018;24(5):348-53.

9. Moher D, Liberati A, Tetzlaff J, Altman DG, PRISMA Group. Preferred reporting items for systematic reviews and meta-analyses: the PRISMA statement. PLoS Med. 2009;6(7):e1000097.

10. Hess G, Borker R, Fonseca E. Treatment patterns: targeted therapies indicated for first-line management of metastatic renal cell carcinoma in a real-world setting. Clin Genitourin Cancer. 2013;11(2):161-67.

11. MacLean E, Cisar L, Mehle K, Eremina D, Quigley JM. Real-world axitinib use in the United States: a retrospective study using linked datasets. J Manag Care Spec Pharm. 2016;22(6):723-32. Available at: https://www.jmcp. org/doi/10.18553/jmcp.2016.22.6.723.

12. Choueiri TK, Duh MS, Clement J, et al. Angiogenesis inhibitor therapies for metastatic renal cell carcinoma: effectiveness, safety and treatment patterns in clinical practice-based on medical chart review. BJU Int. 2010;105(9):1247-54

13. Saleh MN, Haislip S, Sharpe J, et al. Assessment of treatment and monitoring patterns and subsequent outcomes among patients with chronic myeloid leukemia treated with imatinib in a community setting. Curr Med Res Opin. 2014;30(4):529-36.

14. Stenehjem DD, Albright F, Kuo KL, et al. Response monitoring, tolerability, and effectiveness of imatinib treatment for chronic myeloid leukemia in a retrospective research database. J Natl Compr Canc Netw. 2014;12(8):1113-21. 
15. Lu LC, Chen PJ, Yeh YC, et al. Prescription patterns of sorafenib and outcomes of patients with advanced hepatocellular carcinoma: a national population study. Anticancer Res. 2017;37(5):2593-99.

16. Mitra D, Trask PC, Iyer S, Candrilli SD, Kaye JA. Patient characteristics and treatment patterns in chronic myeloid leukemia: evidence from a multi-country retrospective medical record chart review study. Int J Hematol. 2012;95(3):263-73

17. Pal SK, Jonasch E, Signorovitch JE, et al. Real-world dosing and drug costs with everolimus or axitinib as second targeted therapies for advanced renal cell carcinoma: a retrospective chart review in the U.S.J Med Econ. 2016;19(5):462-68

18. Shingina A, Hashim AM, Haque M, et al. In a 'real-world', clinicbased community setting, sorafenib dose of $400 \mathrm{mg}$ /day is as effective as standard dose of $800 \mathrm{mg} /$ day in patients with advanced hepatocellular carcimona, with better tolerance and similar survival. Can J Gastroenterol. 2013;27(7):393-96

19. Bendaly E, Dalal AA, Culver K, et al. Treatment patterns and early outcomes of ALK-positive non-small cell lung cancer patients receiving ceritinib: a chart review study. Adv Ther. 2017;34(5):1145-56.

20. Darkow T, Henk HJ, Thomas SK, et al. Treatment interruptions and nonadherence with imatinib and associated healthcare costs. Pharmacoeconomics. 2007;25(6):481-96

21. Lafeuille M, Grittner AM, Lefebvre P, et al. Adherence patterns for abiraterone acetate and concomitant prednisone use in patients with prostate cancer. J Manag Care Spec Pharm. 2014;20(5):477-84. Available at: https:// www.jmcp.org/doi/10.18553/jmcp.2014.20.5.477.

22. Latremouille-Viau D, Guerin A, Nitulescu R, Gagnon PS, Joseph GJ, Chen L. Treatment patterns and healthcare costs among newly-diagnosed patients with chronic myeloid leukemia receiving dasatinib or nilotinib as first-line therapy in the United States. J Med Econ. 2017;20(1):63-71.

23. Schnadig ID, Hutson TE, Chung H, et al. Dosing patterns, toxicity, and outcomes in patients treated with first-line sunitinib for advanced renal cell carcinoma in community-based practices. Clin Genitourin Cancer 2014;12(6):413-21

24. Castellano D, Duh MS, Korves C, et al. Safety and treatment patterns of angiogenesis inhibitors in patients with advanced renal cell carcinoma in Spain. Expert Opin Drug Saf. 2013;12(4):455-63.
25. Gelderblom H, Judson IR, Benson C, et al. Treatment patterns and clinical outcomes with pazopanib in patients with advanced soft tissue sarcomas in a compassionate use setting: results of the SPIRE study. Acta Oncol. 2017;56(12):1769-75.

26. Porta C, Levy A, Hawkins R, et al. Impact of adverse events, treatment modifications, and dose intensity on survival among patients with advanced renal cell carcinoma treated with first-line sunitinib: a medical chart review across ten centers in five European countries. Cancer Med. 2014;3(6):1517-26.

27. Heijmen L, van Laarhoven HW, Punt CJ, et al. Encouraging results in older patients receiving chemotherapy: a retrospective analysis of treatment guideline adherence in daily practice. Geriatr Gerontol Int. 2012;12(1):80-85.

28. Hayes NA. Analyzing current practice patterns: lessons from Amgen's Project ChemoInsight. Oncol Nurs Forum. 2001;28(2 Suppl):11-16.

29. Denduluri N, Patt DA, Wang Y, et al. Dose delays, dose reductions, and relative dose intensity in patients with cancer who received adjuvant or neoadjuvant chemotherapy in community oncology practices. J Natl Compr Canc Netw. 2015;13(11):1383-93. Available at: https://jnccn.org/abstract/journals/ jnccn/13/11/article-p1383.xml. Accessed August 15, 2019.

30. Jonasch E, Signorovitch JE, Lin PL, et al. Treatment patterns in metastatic renal cell carcinoma: a retrospective review of medical records from U.S. community oncology practices. Curr Med Res Opin. 2014;30(10):2041-50.

31. Tan HS, Li H, Hong YW, et al. Efficacy and safety of an attenuated-dose sunitinib regimen in metastatic renal cell carcinoma: results from a prospective registry in Singapore. Clin Genitourin Cancer. 2015;13(4):e285-95.

32. Filson CP, Redman BG, Dunn RL, Miller DC. Initial patterns of care with oral targeted therapies for patients with renal cell carcinoma. Urology. 2011;77(4):825-30. el.

33. Winn AN, Keating NL, Dusetzina SB. Factors associated with tyrosine kinase inhibitor initiation and adherence among Medicare beneficiaries with chronic myeloid leukemia. J Clin Oncol. 2016;34(36):4323-28. Available at: https://ascopubs.org/doi/10.1200/JCO.2016.67.4184. Accessed August 15, 2019.

34. Lam MS, Cheung N. Impact of oncology pharmacist-managed oral anticancer therapy in patients with chronic myelogenous leukemia. J Oncol Pharm Pract. 2016;22(6):741-48.

35. Amlani A, Kumar A, Ruan JY, Cheung WY. Compliance with adjuvant capecitabine in patients with stage II and III colon cancer: comparison of administrative versus medical record data. Cancer Med. 2016;5(8):1776-82. 


\section{APPENDIX PubMed Search Strategy}

The search was run via www.pubmed.gov and retrieved documents between January 1, 1809, and February 6, 2018.

("antineoplastic agents"[Mesh] OR "antineoplastic agents"[Pharmacological Action] OR "neoplasms/drug therapy"[Mesh] OR "antineoplastic protocols"[Mesh] OR "cytostatic agents"[Mesh] OR "alkylating agents"[Mesh] OR "alkylating agents"[Pharmacological Action] OR chemotherapy[tiab] OR chemotherapeutic*[tiab] OR cytostatic*[tiab] OR anticancer[tiab] OR oncolytic*[tiab] OR oncologic[tiab] OR oncologics[tiab] OR antineoplastic*[tiab] OR antitumor[tiab] OR antitumour[tiab] OR tyrosine kinase inhibitor*[tiab] OR alkylating agent*[tiab] OR angiogenesis inhibitor*[tiab] OR anticarcinogenic*[tiab] OR antimetabolite*[tiab] OR antimitotic*[tiab] OR angiogenesis antagonist*[tiab] OR monoclonal antibodies[tiab] OR monoclonal antibody[tiab])

$$
\text { AND }
$$

("dose-response relationship, drug"[Mesh] OR "drug administration schedule"[Mesh] OR "drug dosage calculations"[Mesh] OR "maximum tolerated dose"[Mesh] OR "no-observed-adverse-effect level"[Mesh] OR "drug evaluation"[Mesh] OR "drug tolerance"[Mesh] OR dosage measur*[tiab] OR dose measur*[tiab] OR initial dose[tiab] OR initial dosage[tiab] OR initial dosing[tiab] OR starting dose[tiab] OR starting dosage[tiab] OR dose intensity[tiab] OR dosing intensity[tiab] OR dosage intensity[tiab] OR dose pattern*[tiab] OR dosage pattern*[tiab] OR dosing pattern*[tiab] OR dosing change*[tiab] OR dose change*[tiab] OR dosage change*[tiab] OR treatment pattern*[tiab] OR dose cycle[tiab] OR dosage cycle[tiab] OR dosing cycle[tiab] OR metronomic dosing[tiab] OR metronomic dosage[tiab] OR metronomic dose[tiab] OR treatment regimen*[tiab] OR dose adjustment*[tiab] OR dosage adjustment*[tiab] OR dosing adjustment*[tiab] OR dose modification*[tiab] OR dosage modification*[tiab] OR dosing modification*[tiab] OR dose delay*[tiab] OR dosing delay*[tiab] OR dose reduction*[tiab] OR dosage reduction*[tiab] OR dosing reduction*[tiab] OR prescribing pattern*[tiab] OR drug holiday*[tiab] OR drug tolerability[tiab] OR patient tolerability[tiab] OR treatment duration[tiab] OR drug tolerance[tiab])

\section{AND}

("medical records"[Mesh] OR "drug utilization review"[Mesh] OR "Registries"[Mesh] OR claims[tiab] OR electronic health record*[tiab] OR medical record*[tiab] OR chart review*[tiab] OR administrative data*[tiab] OR claim data*[tiab] OR drug utilization review*[tiab] OR drug utilisation review*[tiab] OR record review*[tiab] OR registry[tiab] OR registries[tiab]) 